\title{
Unsatisfactory COVID-19-Related Knowledge, Attitudes and Practices among Undergraduate University Students in Uganda: An Online Cross-Sectional Survey
}

\author{
Richard Nyeko ${ }^{*}$, Sharon B. Amanya2 ${ }^{2}$, Mary Aleni ${ }^{3}$, Franceska Akello ${ }^{4}$ \\ ${ }^{1}$ Department of Paediatrics and Child Health, Faculty of Health Sciences, Lira University, Lira, Uganda \\ ${ }^{2}$ Department of Microbiology and Immunology, Faculty of Health Sciences, Lira University, Lira, Uganda \\ ${ }^{3}$ Department of Nursing and Midwifery, Muni University, Arua, Uganda \\ ${ }^{4}$ Department of Paediatrics and Child Health, Faculty of Medicine, Gulu University, Gulu, Uganda \\ Email: ^rnyeko2@gmail.com
}

How to cite this paper: Nyeko, R., Amanya, S.B., Aleni, M. and Akello, F. (2021) Unsatisfactory COVID-19-Related Knowledge, Attitudes and Practices among Undergraduate University Students in Uganda: An Online Cross-Sectional Survey. Open Journal of Preventive Medicine, 11, 259-277.

https://doi.org/10.4236/ojpm.2021.116021

Received: April 26, 2021

Accepted: June 25, 2021

Published: June 28, 2021

Copyright $\odot 2021$ by author(s) and Scientific Research Publishing Inc. This work is licensed under the Creative Commons Attribution International License (CC BY 4.0).

http://creativecommons.org/licenses/by/4.0/ (c) (i) Open Access

\begin{abstract}
Background: This study examined the COVID-19-related knowledge, attitude and practices among undergraduate students in Uganda. Methods: An online cross-sectional survey was conducted from $12^{\text {th }}-19^{\text {th }}$ June 2020 among undergraduate students using a standard questionnaire designed using Google Forms sent via WhatsApp Messenger. The data were analyzed using SPSS. Pearson's Chi-square test was used to test the differences and odds ratios with their $95 \%$ confidence intervals were used for quantifying the association between independent and dependent variables. $\mathrm{p}<0.05$ was considered significant. A cut-off score of $\geq 80 \%$ was used to denote sufficient knowledge, positive attitude, and good practices. Results: Of the 161 respondents, $102(63.4 \%)$ were males with a mean age of 24.2 (5.0) years. The majority 121 (75.2\%) were pursuing health-related programs and overall, $110(68.3 \%)$ had sufficient knowledge while $76(47.2 \%)$ had a positive attitude and good practice each. Knowledge and attitude were significantly associated with health-related programs (AOR 4.78, 95\% CI $2.06-11.07$; p < 0.001) and (AOR 3.18, 95\% CI $1.33-7.62 ; \mathrm{p}=0.010$ ) respectively. The practice was associated with the male gender (AOR 2.37, 95\% CI $1.19-4.73 ; \mathrm{p}=0.014$ ). The most commonly cited sources of COVID-19 information were news media 147 (91.3\%), Ministry of Health 134 (83.2\%), and social media 125 (77.6\%). The ministry of health was considered the most trustworthy source 139 (86.3\%) and social media the least 21 (13.0\%). Conclusions: COVID-19-related knowledge, attitude and practices among undergraduates in Uganda were low
\end{abstract}


overall. Therefore, concerted efforts to provide tailored health education and behaviour change communication are needed.

\section{Keywords}

Knowledge, Attitude, Practice, COVID-19, Undergraduate Students

\section{Introduction}

The Coronavirus Diseases of 2019 (COVID-19) was declared a pandemic by the World Health Organization (WHO) on 11 March 2020 and by 29 June 2020, a landmark 10 million confirmed cases and nearly 500,000 deaths of COVID-19 globally were reported by the WHO [1]. To date (as of $30^{\text {th }}$ March 2021), there were an estimated 126,372,442 global confirmed cases, at least 3,061,438 of the cases and 77,446 deaths were in African countries [1]. Uganda recorded its first case of COVID-19 on 21 March 2020 and as of 31 March 2021, the country had 40,767 confirmed cases and 335 reported deaths [1].

COVID-19 is a highly infectious disease believed to spread through respiratory aerosol generated through coughing and sneezing by an infected person [2] [3]. Evidence also suggests that a proportion of asymptomatic and mildly ill COVID-19 cases do also spread the disease [4]. However, the mode of transmission, just as its pathophysiology is still cloudy. The main clinical symptoms of COVID-19 include fever, dry cough, fatigue/myalgia, and difficulty in breathing. Other symptoms are sore throat, diarrhoea, loss of taste or smell, and arthralgia [5] [6] [7] [8]. About $20 \%$ of patients can develop severe disease characterized by acute respiratory distress syndrome (ARDS) requiring oxygen therapy and about $5 \%$ will require intensive care unit treatment including mechanical ventilation [9].

To date, there is no proven antiviral treatment or vaccine against SARS-CoV-2, the virus responsible for the current COVID-19 pandemic [8]. Containment of the pandemic, therefore, centres primarily on strong and strict infection control measures arising from the knowledge of the mechanisms of its transmission, to minimize the spread of the infection within the population [10] [11] [12]. The primary preventive measures are largely behavioural and include regular hand washing, social distancing, respiratory hygiene [11] [12], and use of face masks in public, compliance with which is largely dependent on the change in behaviour which is shaped by one's knowledge about the disease and their attitude [6] [8]. While there has been a breakthrough in vaccine development, with several vaccine candidates currently under emergency use in different parts of the world, the global impact is yet to be realized. Uganda launched the COVID-19 vaccination using the Astra-Zeneca vaccine on the $10^{\text {th }}$ of March 2021, targeting mainly frontline healthcare workers, the elderly and persons with preexisting health conditions associated with increased risk of COVID-19 morbidity and 
mortality. Vaccine uptake has generally remained low with only approximately 180,969 having been vaccinated as of $10^{\text {th }}$ April 2021-a month since its launch, and the country is yet to realize any meaningful impact of the vaccine.

University students are among the most exposed to a wide range of information, including social media where misinformation abounds, and yet are not among the current targets of the COVID-19 vaccination drive. This has the potential of clouding their understanding of the current COVID-19 pandemic [13], with dire consequences. To date, there is a paucity of data on knowledge, attitude, and practices related to the current COVID-19 pandemic among undergraduate students undertaking various study programs in Sub Saharan Africa, Uganda inclusive. This study, therefore, aimed to assess the COVID-19-related knowledge, attitude, and practices among undergraduate university students in Uganda to recognize socio-demographic factors which can be useful in sanctioning behaviour change.

\section{Materials and Methods}

\subsection{Study Design}

This was an online cross-sectional survey conducted from $12^{\text {th }}-19^{\text {th }}$ June 2020 , to determine the knowledge, attitude, and practices related to COVID-19 among the respondents.

\subsection{Study Setting}

The study was conducted at three Universities in the northern region of Uganda, namely; Lira, Gulu and Muni Universities. The northern region comprises three sub-regions with distinct indigenous populations and is located approximately 360 - 600 km from Kampala, Uganda's capital city.

\subsection{Study Population}

The study targeted students undertaking various undergraduate programs at different years of studies at the three universities.

\subsection{Sample Size Determination}

The sample size was estimated at 285 using the single population proportion formula [14] based on an average previous estimate of good knowledge related to COVID-19 of 79.9\% [15], with a marginal error of 5\%, a standard normal value corresponding to $95 \%$ certainty, and a non-response rate of $15 \%$.

\subsection{Study Instrument}

A precoded structured questionnaire was used to collect quantitative data, developed with questions adapted from previous peer-reviewed KAP surveys [6] [16] [17] and the national COVID-19 Diagnosis and Treatment Protocol [18]. The questionnaire consisted of four parts: 1) Socio-demographic characteristics, 2) Knowledge questions, 3) Attitude-based questions, and 4) Practice questions. 


\subsection{Sampling Procedure and Data Collection}

Because the country was in a lockdown with all learning institutions, including the universities, closed, we opted for an online platform using WhatsApp Messenger (Facebook, Inc., California, USA) to enroll potential participants. We employed a convenient sampling method and identified all the existing WhatsApp groups of the undergraduate students in the three universities. The Google Form link to the questionnaire was sent via WhatsApp Messenger (Facebook, Inc., California, USA) to identified students' WhatsApp groups.

\section{Study Variables}

\subsection{Independent Variables}

The independent variables included respondents' age; gender; year of study; institution, academic program, previous qualifications, residence, and source of information.

\subsection{Dependent Variables}

Respondents' COVID-19-related knowledge, attitude and practices formed the dependent variables.

The knowledge domain was assessed using a 15-item question, aimed at assessing the general knowledge about the cause, transmission, clinical presentation, risk factors and prevention of COVID-19 answered largely on a true or false basis with an additional option of "I don't know" for those who are uncertain. Each correct response weighed 1 point and 0 points for incorrect or uncertain responses, giving a maximum score of 15 and a minimum score of 0 . The higher the points scored, the more knowledgeable the student.

The attitude domain was assessed using a 10-item question, each based on a 5 Likert scale with responses of strongly disagree, disagree, not sure, agree, and strongly agree. A score of 1 was assigned for a response reflecting a positive attitude and 0 for a response reflecting a negative attitude or neutral response, giving a maximum score of 10 and a minimum score of 0 .

The practice of COVID-19 prevention was assessed using a 7-item question to assess the actual uptake of, and adherence to, the primary preventive measures for COVID-19. Each item was based on a response of "always", "sometimes" and "never" or as specified. A weight of 1 was given for a response reflecting good practice and 0 for a response reflecting poor practice, giving a maximum score of 7 and a minimum score of 0 .

Students' KAP levels will be defined as "good"/"sufficient" or "poor"/“insufficient" based on cut off points adapted from that used in previous KAP studies [17] [19]. For knowledge assessment, scores of $80 \%$ and above will be regarded as sufficient knowledge, while those below $80 \%$ will be taken to reflect insufficient knowledge. For attitude, scores of $80 \%$ and above will be regarded as reflecting a good attitude, while scores below $80 \%$ will be regarded as a poor attitude. For practice, students with scores of $\geq 80 \%$ will be categorized as having good pre- 
ventive practice, while those with scores $<80 \%$ will be considered as having poor preventive practice [20].

\subsection{Data Management and Statistical Analysis}

The completed questionnaires were extracted from Google Forms into Microsoft Excel 2010 and the data was exported to Statistical Package for Social Sciences (SPSS) software package (SPSS for Windows, Version 16.0. Chicago, SPSS Inc.) for analysis. Descriptive statistics were calculated for demographic characteristics and responses to given KAP questions, and summarized as frequencies (percentages) for categorical variables and mean (standard deviation) or median (interquartile range) for continuous variables. A cut-off of $80 \%$ was used to categorize sufficient knowledge, positive attitude and good practice. Pearson's Chi-square test was used to test the differences between socio-demographic characteristics with regards to KAP, and multivariate logistic regression analysis was used to determine the association between the socio-demographic variables and KAP. Variables with p-value $<0.3$ on bivariate analysis were entered into the multivariate model. The adjusted odds ratios (AOR) and their $95 \%$ confidence intervals (CIs) were used to quantify the associations between socio-demographic variables and KAP. $\mathrm{p}<0.05$ was considered for statistical significance.

\subsection{Ethics Approval Considerations}

The study was approved by the Lacor Hospital Institutional Research and Ethics Committee [approval number LHIREC 0165/05/2020]. Online informed consent was made accessible to the respondents and informed consent was obtained before participating in the study. The questionnaire was designed to be anonymous and respondents were informed that all information provided would be anonymous and confidential.

\section{Results}

\subsection{Socio-Demographic Characteristics of the Respondents}

A total of 162 participants completed the online survey questionnaire, giving a response rate of $57 \%$. After validating the data, 1 respondent was excluded and a final sample of 161 was analyzed. The age range was $19-56$ years, median (IQR) 23 (22 - 24) years and mean 24.2 (SD 5.0) years. Up to 75.2\% (121/161) were pursuing health-related programs while $40(24.8 \%)$ were pursuing non-health-related programs. The main sources of information about COVID-19 were News media 147 (91.3\%), Ministry of health sites 134 (83.2\%) and social media 125 (77.6\%). The trust in these sources varied widely, with the ministry of health sources being rated as the most trustworthy by 136 (86.3\%) of the respondents, while only $21(13.0 \%)$ of the respondents rated social media as a trustworthy source of COVID-19 information (Table 1). 
Table 1. Demographic characteristics of the respondents.

\begin{tabular}{|c|c|c|}
\hline Variable & Frequency & Percentage \\
\hline \multicolumn{3}{|l|}{ Gender } \\
\hline Male & 102 & 63.4 \\
\hline Female & 59 & 36.6 \\
\hline \multicolumn{3}{|l|}{ Age (years) } \\
\hline Mean (SD) & $24.2(5.0)$ & \\
\hline $19-23$ & 102 & 63.4 \\
\hline$\geq 24$ & 59 & 36.6 \\
\hline \multicolumn{3}{|l|}{ Institution } \\
\hline Lira University & 66 & 41.0 \\
\hline Gulu University & 51 & 31.7 \\
\hline Muni University & 44 & 27.3 \\
\hline \multicolumn{3}{|l|}{ Study program } \\
\hline Health-related Course & 121 & 75.2 \\
\hline Non-health-related Course & 40 & 24.8 \\
\hline \multicolumn{3}{|l|}{ Year of study } \\
\hline $1^{\text {st }}$ year & 18 & 11.2 \\
\hline $2^{\text {nd }}$ year & 34 & 21.1 \\
\hline $3^{\text {rd }}$ year & 57 & 35.4 \\
\hline $4^{\text {th }}$ year & 39 & 24.2 \\
\hline $5^{\text {th }}$ year & 13 & 8.1 \\
\hline \multicolumn{3}{|l|}{ Previous qualifications } \\
\hline Yes & 25 & 15.5 \\
\hline No & 136 & 84.5 \\
\hline \multicolumn{3}{|l|}{ Type of the previous qualification } \\
\hline Certificate & 3 & 1.9 \\
\hline Diploma & 22 & 13.7 \\
\hline None & 136 & 84.4 \\
\hline \multicolumn{3}{|l|}{ Residence during lockdown } \\
\hline Rural & 69 & 42.9 \\
\hline Urban & 92 & 57.1 \\
\hline \multicolumn{3}{|l|}{ Source of information on COVID-19 } \\
\hline International health organizations & 104 & 64.6 \\
\hline Ministry of Health sites & 134 & 83.2 \\
\hline TVs, Radios \& Newspapers & 147 & 91.3 \\
\hline Social Media & 125 & 77.6 \\
\hline Others & 6 & 3.7 \\
\hline \multicolumn{3}{|l|}{ The most trusted source of information } \\
\hline International health organizations & 95 & 59.0 \\
\hline Ministry of Health & 139 & 86.3 \\
\hline TVs, Radios \& Newspapers & 74 & 46.0 \\
\hline Social Media & 21 & 13.0 \\
\hline Others & 10 & 6.2 \\
\hline
\end{tabular}

\subsection{Respondents' COVID-19-Related Knowledge}

The total knowledge score to the 15-item knowledge questions ranged from $40 \%$ 
$(6 / 15)$ to $100 \%(15 / 15)$. Nearly all, $156(96.9 \%)$ were aware that COVID-19 is a viral infectious disease, while all 161 (100\%) were familiar with the main mode of transmission. The majority were able to identify fever 157 (97.5\%), shortness of breath $146(90.7 \%)$ and cough $146(90.7 \%)$ as the main clinical symptoms of COVID-19, though only $60(37.3 \%)$ were aware of myalgia as one of the main symptoms. Table 2 summarizes the knowledge levels on various aspects of COVID-19.

The mean knowledge score was 12.0 (SD 1.5) with an overall knowledge score of $68.3 \%$, indicating a low knowledge of COVID-19 (Table 3). When correlated against the baseline socio-demographic characteristics of the respondents, there was a statistically significant difference in knowledge levels on COVID-19 between students undertaking health-related programs and those undertaking non-health-related programs on bivariate analysis $\left(\chi^{2} 16.4 ; \mathrm{p}<0.001\right)$. Likewise, there was a statistically significant difference in knowledge levels with regards to the use of the ministry of health as the main source of information about COVID-19 $\left(\chi^{2} 6.10 ; p=0.014\right)$. There was no statistically significant difference in knowledge levels for the rest of the socio-demographic characteristics on the bivariate analysis (Table 3 ).

On multivariate analysis, the study program was the only factor that significantly influenced the level of COVID-19-related knowledge among the respondents. Students pursuing health-related programs were more likely to have sufficient knowledge about COVID-19 than those pursuing non-health-related programs (AOR 4.78, 95\% CI 2.06 - 11.07; p < 0.001). Respondents' age, year of study, previous qualifications, and source of information did not significantly influence knowledge levels (Table 3).

\subsection{Respondents' Attitude towards COVID-19}

Notably, $28(17.4 \%)$ of the respondents believed that being a black race confers less risk of COVID-19 infection and only 56 (34.8\%) were confident that Uganda is in a good position to contain the infection. Likewise, only 66 (41.0\%) were confident that the school environment was enabling in preventing the spread of COVID-19. The majority 153 (95.0\%) of the students believed the pandemic has impacted on their study, while $138(85.7 \%)$ were willing to help in the frontline rescue if needed (Table 4 ).

The overall positive towards COVID-19 was $47.2 \%(76 / 161)$-indicating that the attitude among the undergraduate students was generally negative (Table 5). There was a statistically significant difference in attitude between students undertaking health-related programs and those undertaking non-health-related programs $\left(\chi^{2} 4.62 ; \mathrm{p}=0.032\right)$. There was also no statistically significant difference in attitude with regards to the rest of the socio-demographic characteristics on bivariate analysis (Table 5).

On multivariate analysis, students undertaking health-related programs were more likely to have a positive attitude towards COVID-19 than those pursuing 
Table 2. Knowledge of the undergraduate students about COVID-19.

\begin{tabular}{|c|c|}
\hline Knowledge question & $\begin{array}{l}\text { Correct response } \\
\mathrm{N}(\%)\end{array}$ \\
\hline K1 _ What type of infectious disease is COVID-19? & $156(96.9)$ \\
\hline $\mathrm{K} 2$ _ What is the main transmission route of COVID-19? & $161(100)$ \\
\hline K3 _ How long is the COVID-19 incubation period? & $150(93.2)$ \\
\hline K4 _ Who is susceptible to COVID-19? & $100(62.1)$ \\
\hline $\begin{array}{l}\text { K5 _ Persons with COVID-19 cannot infect others if they do not have } \\
\text { signs and symptoms of COVID-19 like fever, cough, etc. }\end{array}$ & $143(88.8)$ \\
\hline $\begin{array}{l}\text { K6_ Eating or getting into contact with wild animals would result in } \\
\text { infection with the coronavirus }\end{array}$ & $67(41.6)$ \\
\hline K7 _ What are the main clinical symptoms of COVID-19? (overall) & $52(32.3)$ \\
\hline Fever & $157(97.5)$ \\
\hline Shortness of breath & $146(90.7)$ \\
\hline Cough & $146(90.7)$ \\
\hline Myalgia & $60(37.3)$ \\
\hline K8 _ Other clinical symptoms of COVID-19 & $46(28.6)$ \\
\hline $\begin{array}{l}\text { K9 _ Those at risk of severe disease include the elderly, those with } \\
\text { pre-existing chronic illnesses, and children }<1 \text { year. }\end{array}$ & $126(78.3)$ \\
\hline $\begin{array}{l}\mathrm{K} 10 \text { _ There is no treatment for COVID-19 but early symptomatic \& } \\
\text { supportive treatment can help most patients recover from the infection. }\end{array}$ & $158(98.1)$ \\
\hline K11 _ Wearing general medical masks can prevent one from COVID-19 & $144(89.4)$ \\
\hline $\begin{array}{l}\text { K12_ Children and young adults do not need to take measures to } \\
\text { prevent the infection by the COVID-19 because they are at low risk. }\end{array}$ & $146(90.7)$ \\
\hline $\begin{array}{l}\text { K13 - To prevent the infection by COVID-19, individuals should } \\
\text { avoid going to crowded places }\end{array}$ & $158(98.1)$ \\
\hline $\begin{array}{l}\text { K14_ Isolation and treatment of people who are infected with the } \\
\text { COVID-19 virus are effective ways to reduce the spread of the virus. }\end{array}$ & $161(100)$ \\
\hline $\begin{array}{l}\text { K15_People who have contact with someone infected with the } \\
\text { COVID-19 virus should be immediately isolated for } 14 \text { days. }\end{array}$ & $159(98.8)$ \\
\hline
\end{tabular}

other programs (AOR 3.18, 95\% CI 1.33 - 7.62; $\mathrm{p}=0.010$ ). Likewise, second-year students, regardless of the study program, were significantly more likely to have a positive attitude towards COVID-19 than first-year students (AOR 5.75 (95\% CI $1.41-23.55 ; \mathrm{p}=0.015$ ), and so were the third-year students (AOR 7.26, 95\% CI 1.92 - 27.45; $\mathrm{p}=0.004$ ), fourth-year students (AOR 9.20, 95\% CI 2.9 - 38.73; $\mathrm{p}=0.002)$ and fifth-year students (AOR 7.19, 95\% CI $1.29-40.03 ; \mathrm{p}=0.024$ ) (Table 5).

\subsection{COVID-19 Prevention Practices among the Respondents}

In responding to questions assessing observance of the COVID-19 preventive practices, only 77 (44.7\%) had avoided a crowded place in the period preceding the study and just over half, 88 (54.7\%) had worn a mask when leaving home. When asked about what they would do if they had a fever and dry cough, the 
Table 3. Socio-demographic characteristics associated with knowledge on COVID-19 among the undergraduate university students.

\begin{tabular}{|c|c|c|c|c|c|c|c|}
\hline \multirow[b]{2}{*}{ Characteristic } & \multirow[b]{2}{*}{ Mean score } & \multicolumn{4}{|c|}{ Bivariate } & \multicolumn{2}{|c|}{ Multivariate } \\
\hline & & $\begin{array}{c}\text { Sufficient } \\
\text { Knowledge N } \\
(\%)\end{array}$ & $\begin{array}{c}\text { Insufficient } \\
\text { knowledge } \\
\mathrm{N}(\%)\end{array}$ & $\chi^{2}$ & $P$-value & $\operatorname{AOR}(95 \% \mathrm{CI})$ & $P$-value \\
\hline Overall Score & $12.0 \pm 1.5$ & $110(68.3)$ & $51(31.7)$ & NA & & - & - \\
\hline \multicolumn{8}{|l|}{ Gender } \\
\hline Male & $12.0 \pm 1.4$ & $70(63.7)$ & $32(62.7)$ & 0.01 & 0.913 & - & - \\
\hline Female & $11.8 \pm 1.5$ & $40(36.4)$ & $19(37.3)$ & & & & \\
\hline \multicolumn{8}{|l|}{ Age (years) } \\
\hline $19-23$ & $11.9 \pm 1.3$ & $66(60.0)$ & $36(70.6)$ & 1.68 & 0.195 & $0.68(0.23-2.03)$ & 0.492 \\
\hline$\geq 24$ & $12.0 \pm 1.7$ & $44(40.0)$ & $15(29.4)$ & & & 1.0 & \\
\hline \multicolumn{8}{|l|}{ Institution } \\
\hline Lira University & $12.0 \pm 1.6$ & $46(41.8)$ & $20(39.2)$ & 1.19 & 0.553 & - & - \\
\hline Gulu University & $11.9 \pm 1.4$ & $32(29.1)$ & $19(37.3)$ & & & & \\
\hline Muni University & $11.9 \pm 1.3$ & $32(29.1)$ & $12(23.5)$ & & & & \\
\hline \multicolumn{8}{|l|}{ Study program } \\
\hline Health-related & $12.2 \pm 1.4$ & $93(84.5)$ & $28(54.9)$ & 16.4 & $<0.001^{*}$ & $4.78(2.06-11.07)$ & $<0.001^{*}$ \\
\hline Non-health-related & $11.2 \pm 1.5$ & $17(15.5)$ & $23(45.1)$ & & & 1.0 & \\
\hline \multicolumn{8}{|l|}{ Year of study } \\
\hline $1^{\text {st }}$ year & $11.6 \pm 1.4$ & $10(9.1)$ & $8(15.7)$ & 5.46 & 0.243 & 1.0 & \\
\hline $2^{\text {nd }}$ year & $12.0 \pm 1.4$ & $20(18.2)$ & $14(27.5)$ & & & $1.09(0.31-3.89)$ & 0.890 \\
\hline $3^{\text {rd }}$ year & $11.8 \pm 1.5$ & $39(18.2)$ & $18(35.3)$ & & & $0.66(0.20-2.19)$ & 0.499 \\
\hline $4^{\text {th }}$ year & $12.2 \pm 1.5$ & $31(28.2)$ & $8(15.7)$ & & & $0.49(0.11-2.20)$ & 0.350 \\
\hline $5^{\text {th }}$ year & $12.2 \pm 1.5$ & $10(9.1)$ & $3(5.9)$ & & & $0.70(0.10-4.79)$ & 0.719 \\
\hline \multicolumn{8}{|l|}{ Prev. qualification } \\
\hline Yes & $12.6 \pm 1.4$ & $21(19.1)$ & $4(7.8)$ & 3.36 & 0.067 & $3.12(0.74-13.13)$ & 0.122 \\
\hline No & $11.9 \pm 1.4$ & $89(80.9)$ & $47(92.2)$ & & & 1.0 & \\
\hline \multicolumn{8}{|l|}{ Residence } \\
\hline Rural & $12.3 \pm 1.5$ & $48(43.6)$ & $21(41.2)$ & 0.09 & 0.769 & - & - \\
\hline Urban & $11.8 \pm 1.4$ & $62(56.4)$ & $30(58.8)$ & & & & \\
\hline \multicolumn{8}{|l|}{ Information source } \\
\hline International & $12.3 \pm 1.3$ & $74(67.3)$ & $30(58.8)$ & 1.09 & 0.297 & $0.87(0.35-2.15)$ & 0.766 \\
\hline Ministry of Health & $12.1 \pm 1.3$ & $97(88.3)$ & $37(72.5)$ & 6.10 & $0.014^{*}$ & $2.65(0.89-7.86)$ & 0.079 \\
\hline TVs, Radios, etc & $12.0 \pm 14$ & $100(90.9)$ & $47(92.2)$ & 0.07 & 0.794 & & \\
\hline Social Media & $11.9 \pm 1.4$ & $85(77.3)$ & $40(78.4)$ & 0.03 & 0.870 & & \\
\hline Others & $12.0 \pm 1.5$ & $5(4.5)$ & $1(2.0)$ & 0.65 & 0.421 & & \\
\hline
\end{tabular}

NA = Not applicable; Prev. qualification $=$ Previous qualification; AOR = Adjusted Odds Ratio; ${ }^{*}$-value significant.

majority, 159 (98.8\%) would self-quarantine or go to the hospital for treatment, while $2(1.2 \%)$ would hide or go to a clinic or buy some medicine and self-medicate. Participants' responses to the other COVID-19 preventive practices are as summarized in Table 6.

Overall, only 76 (47.2\%) of the respondents demonstrated good COVID-19 prevention practices (Table 7). There was a statistically significant difference in COVID-19 prevention practices by gender on bivariate analysis $\left(\chi^{2} 5.49 ; \mathrm{p}=\right.$ 
Table 4. Respondents' response concerning attitude towards COVID-19.

\begin{tabular}{|c|c|c|c|c|c|}
\hline \multirow[b]{2}{*}{ Attitude question } & \multicolumn{5}{|c|}{ Response* } \\
\hline & $\begin{array}{c}\mathrm{SD} \\
\mathrm{N}(\%)\end{array}$ & $\begin{array}{c}\mathrm{D} \\
\mathrm{N}(\%)\end{array}$ & $\begin{array}{c}\text { NS } \\
\text { N (\%) }\end{array}$ & $\begin{array}{c}\text { A } \\
\mathrm{N}(\%)\end{array}$ & $\begin{array}{c}\text { SA } \\
\mathrm{N}(\%)\end{array}$ \\
\hline A1 _ Being of black race makes one less prone to infection with the COVID-19 virus. & $70(43.5)$ & $41(25.5)$ & $22(13.7)$ & $19(11.8)$ & $9(5.6)$ \\
\hline A2 _ Wearing a well-fitting face mask is effective in preventing COVID-19. & $10(6.2)$ & $8(5.0)$ & $4(2.5)$ & $80(49.7)$ & $59(36.6)$ \\
\hline A3 _ Using a hand wash can prevent you from getting COVID-19. & $7(3.4)$ & $3(1.9)$ & $1(0.6)$ & $93(57.8)$ & $57(35.4)$ \\
\hline A4__Uganda is in a good position to contain COVID- 19. & $22(13.7)$ & $54(33.5)$ & $29(18.0)$ & $44(27.3)$ & $12(7.5)$ \\
\hline A5 _ Are you scared by the person-person transmission of COVID-19? & $2(1.2)$ & $17(10.6)$ & $2(1.2)$ & $88(54.7)$ & $52(32.3)$ \\
\hline A6 _ Do you hope the outbreak stops fast so you can return to school soon? & $14(8.7)$ & $9(5.6)$ & $16(9.9)$ & $33(20.5)$ & $89(55.3)$ \\
\hline $\begin{array}{l}\text { A7 _ Do you think you will be more capable of the endurance of such a public health } \\
\text { emergency? }\end{array}$ & $7(4.3)$ & $21(13.0)$ & $32(19.9)$ & $68(42.2)$ & $33(20.5)$ \\
\hline A8 _ Do you think this outbreak has impacted your study? & $5(3.1)$ & $1(0.6)$ & $2(1.2)$ & $17(10.6)$ & $136(84.5)$ \\
\hline A9 _ Are you confident in the school environment in preventing the spread of COVID-19? & $38(23.6)$ & $35(21.7)$ & $22(13.7)$ & $47(29.2)$ & $19(11.8)$ \\
\hline A10 _ If the country needs you, are you willing to help the frontline rescue? & $6(3.7)$ & $5(3.1)$ & $12(7.5)$ & $57(35.4)$ & $81(50.3)$ \\
\hline
\end{tabular}

${ }^{*} \mathrm{SD}=$ Strongly Disagree; $\mathrm{D}$ = Disagree; NS = Not Sure; A = Agree; SA = Strongly Agree.

0.019), but not the other socio-demographic characteristics (Table 7). On multivariate analysis, gender remained the only socio-demographic characteristic that independently influenced practice, where male students were significantly more likely to exhibit good preventive practices than their female counterparts (AOR 2.37, 95\% CI 1.19 - 4.73; p = 0.014) (Table 7).

\section{Discussion}

The current COVID-19 pandemic has had devastating global effects on all spheres of human life since first reported in Wuhan, China, in December 2019 and subsequently declared a pandemic by WHO in March 2020. In the absence of proven vaccine or treatment, strong and strict infection control measures to prevent its spread are crucial, compliance to which is influenced by individuals' knowledge, attitude, and practices. To date, there has been limited published data on KAP among university students in Sub Saharan Africa (SSA) and to the best of our knowledge; this is the first study in investigating COVID-19-related KAP among university students undertaking programs beyond the medical field. The study assessed COVID-19-related KAP among students in three public universities in Uganda to recognize socio-demographic factors which can be useful in sanctioning behaviour change.

\subsection{COVID-19-Related Knowledge}

Overall, 68.3\% of the students had sufficient COVID-19-related knowledge, a level much lower than that reported among medical students in Uganda (90\%) [21], Iran (87\%) [22], China (82.34\%) [16] and Pakistan (79.9\%) [15]. However, the knowledge level among undergraduate students in our study is higher than 10.5\% and 37.5\% reported among students in Bangladesh [23] and Saudi Arabia [24] respectively. This could be attributed to the difference in the study populations 
Table 5. Socio-demographic characteristics associated with Attitude towards COVID-19 among the undergraduate university students.

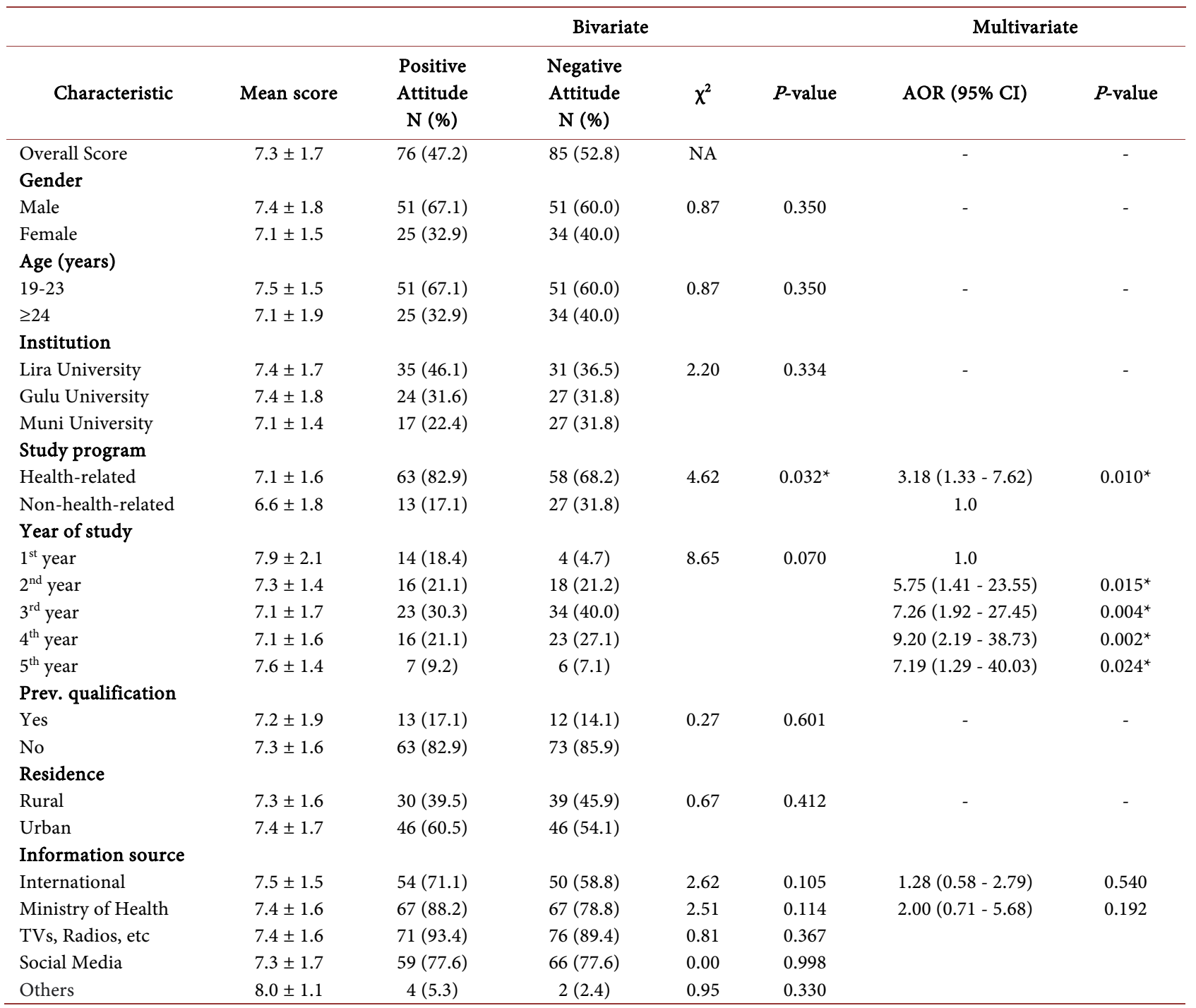

NA = Not applicable; Prev. qualification = Previous qualification; AOR = Adjusted Odds Ratio, ${ }^{*}$-value significant.

Table 6. Participants' response to practice questions concerning COVID-19 preventive measures.

\begin{tabular}{|c|c|c|c|}
\hline \multirow[b]{2}{*}{ Practice question } & \multicolumn{2}{|c|}{ Response } & \multirow[b]{2}{*}{$\begin{array}{l}\text { Never } \\
\mathrm{N}(\%)\end{array}$} \\
\hline & $\begin{array}{l}\text { Always } \\
\text { N (\%) }\end{array}$ & $\begin{array}{l}\text { Sometimes } \\
\mathrm{N}(\%)\end{array}$ & \\
\hline P1_ In recent days, have you gone to any crowded place? & $11(6.8)$ & $78(48.4)$ & $71(44.7)$ \\
\hline $\mathrm{P} 2$ _ In recent days, have you worn a mask when leaving home? & $88(54.7)$ & $54(33.5)$ & $19(11.8)$ \\
\hline P3 _ In recent days, have you refrained from shaking hands? & $116(72.0)$ & $36(22.4)$ & $9(5.6)$ \\
\hline \multirow[t]{2}{*}{ P4 _ In recent days, have you washed your hands at all times and before and after touching anything? } & $91(56.5)$ & $70(43.5)$ & $0(0.0)$ \\
\hline & Right action & Wrong action & Unsure \\
\hline P5 _ What would you do if you had close contact with a confirmed case of COVID-19? & $156(96.9)$ & $5(3.1)$ & $0(0.0)$ \\
\hline P6 _ What would you do if you had a fever and dry cough? & $159(98.8)$ & $2(1.2)$ & $0(0.0)$ \\
\hline $\begin{array}{l}\text { P7 _ What would you do if a colleague or your classmate who cured of COVID-19 wanted to meet } \\
\text { you or is to attend class with you? }\end{array}$ & $145(90.1)$ & $5(3.1)$ & $11(6.8)$ \\
\hline
\end{tabular}


Table 7. Socio-demographic characteristics associated with COVID-19 prevention practice among the undergraduate university students.

\begin{tabular}{|c|c|c|c|c|c|c|c|}
\hline \multirow[b]{2}{*}{ Characteristic } & \multirow[b]{2}{*}{ Mean score } & \multicolumn{4}{|c|}{ Bivariate } & \multicolumn{2}{|c|}{ Multivariate } \\
\hline & & $\begin{array}{c}\text { Good Practice } \\
\text { N (\%) }\end{array}$ & $\begin{array}{c}\text { Poor Practice } \\
\text { N (\%) }\end{array}$ & $\chi^{2}$ & $P$-value & $\operatorname{AOR}(95 \% \mathrm{CI})$ & $P$-value \\
\hline Overall Score & $5.1 \pm 1.3$ & $76(47.2)$ & $85(52.8)$ & NA & & & \\
\hline \multicolumn{8}{|l|}{ Gender } \\
\hline Male & $5.0 \pm 1.4$ & $41(53.9)$ & $61(71.8)$ & 5.49 & $0.019^{*}$ & $2.37(1.19-4.73)$ & $0.014^{\star}$ \\
\hline Female & $5.5 \pm 1.1$ & $35(46.1)$ & $24(28.2)$ & & & 1.0 & \\
\hline \multicolumn{8}{|l|}{ Age (years) } \\
\hline $19-23$ & $5.2 \pm 1.3$ & $52(68.1)$ & $50(58.8)$ & 1.59 & 0.207 & $0.72(0.37-1.41)$ & 0.338 \\
\hline$\geq 24$ & $5.0 \pm 1.5$ & $24(31.6)$ & $35(41.2)$ & & & 1.0 & \\
\hline \multicolumn{8}{|l|}{ Institution } \\
\hline Lira University & $5.3 \pm 1.4$ & $32(42.1)$ & $34(40.0)$ & 1.24 & 0.538 & - & - \\
\hline Gulu University & $5.0 \pm 1.4$ & $21(27.6)$ & $30(35.3)$ & & & & \\
\hline Muni University & $5.1 \pm 1.3$ & $23(30.3)$ & $21(24.7)$ & & & & \\
\hline \multicolumn{8}{|l|}{ Study program } \\
\hline Health-related & $5.1 \pm 1.5$ & $58(76.3)$ & $63(74.1)$ & 1.10 & 0.747 & - & - \\
\hline Non-health-related & $5.3 \pm 1.1$ & $18(23.7)$ & $22(25.9)$ & & & & \\
\hline \multicolumn{8}{|l|}{ Year of study } \\
\hline $1^{\text {st }}$ year & $5.6 \pm 1.3$ & $10(13.2)$ & $8(9.4)$ & 1.21 & 0.876 & - & - \\
\hline $2^{\text {nd }}$ year & $5.1 \pm 1.2$ & $17(22.4)$ & $17(20.0)$ & & & & \\
\hline $3^{\text {rd }}$ year & $5.2 \pm 1.4$ & $27(35.5)$ & $30(35.3)$ & & & & \\
\hline $4^{\text {th }}$ year & $5.0 \pm 1.2$ & $16(21.1)$ & $23(27.1)$ & & & & \\
\hline $5^{\text {th }}$ year & $4.0 \pm 2.0$ & $6(7.9)$ & $7(8.2)$ & & & & \\
\hline \multicolumn{8}{|l|}{ Prev. qualification } \\
\hline Yes & $5.3 \pm 1.3$ & $13(17.1)$ & $12(14.1)$ & 0.27 & 0.601 & - & - \\
\hline No & $5.1 \pm 1.4$ & $63(82.9)$ & $73(85.9)$ & & & & \\
\hline \multicolumn{8}{|l|}{ Residence } \\
\hline Rural & $5.1 \pm 1.4$ & $31(40.8)$ & $38(44.7)$ & 0.25 & 0.616 & - & - \\
\hline Urban & $5.2 \pm 1.3$ & $35(59.2)$ & $47(55.3)$ & & & & \\
\hline \multicolumn{8}{|l|}{ Information source } \\
\hline International & $5.3 \pm 1.3$ & $53(69.7)$ & $51(60.0)$ & 1.66 & 0.197 & $0.52(0.26-1.05)$ & 0.067 \\
\hline Ministry of Health & $5.1 \pm 1.4$ & $65(85.5)$ & $69(81.2)$ & 0.54 & 0.461 & & \\
\hline TVs, Radios, etc & $5.1 \pm 1.4$ & $69(90.8)$ & $78(91.8)$ & 0.05 & 0.826 & & \\
\hline Social Media & $5.2 \pm 1.3$ & $60(78.9)$ & $65(76.5)$ & 0.14 & 0.707 & & \\
\hline Others & $5.3 \pm 0.8$ & $3(3.9)$ & $3(3.5)$ & 0.02 & 0.889 & & \\
\hline
\end{tabular}

$\mathrm{NA}=$ Not applicable; Prev. qualification = Previous qualification; AOR = Adjusted Odds Ratio, ${ }^{\star} \mathrm{p}$-value significant.

and the parameters used in assessing knowledge. For instance, unlike the other studies, the current study assessed knowledge among a mixed group of students across various non-medical disciplines based on a more diverse criterion on a 15-item question.

In this study, COVID-19-related knowledge was significantly associated with 
the study program pursued, being significantly higher among students undertaking health-related programs than their counterparts. This finding is consistent with that reported in other studies [15] [16] [24] and has been attributed to the training of these students in clinical medicine and public health, as well as their sense of duty and responsibility as a candidate medical professional [25]. Contrary to findings from other pieces of literature [15] [26], age, education, institution, year of study, and source of information did not significantly influence the level of knowledge about COVID-19 among undergraduate university students in the current study.

The study found a high level of knowledge regarding COVID-19 aetiology, its main route of transmission, the incubation period and the groups at high risk. This finding is similar to that reported among undergraduate students in Pakis$\tan [15]$ and Saudi Arabia [24]. This is important because knowledge of the aetiology, transmissibility of, and susceptibility to, the disease is considered as the first step of individuals education and behaviour change communication in adopting the preventive measures that limit its spread [27]. In the same breath, the knowledge that asymptomatic persons of COVID-19 can still transmit the infection to others was high among the respondents. This finding is critical in shaping behaviour change to observe the preventive measures in all situations since the available body of evidence indicates that mild or asymptomatic COVID-19 cases may spread the disease [4]. Furthermore, the current finding reveals that while only $32.3 \%$ of participants were aware of all the main symptoms of COVID-19, awareness of the individual symptoms of fever, cough, and shortness of breath as the top main symptoms of COVID-19 were generally high. However, only $37.3 \%$ knew that myalgia was one of the symptoms of the disease. This finding resonates with that reported in other studies [15] [21] [28] where knowledge of myalgia as one of the main symptoms of COVID-19 was limited. Given that COVID-19 is largely a respiratory disease, this finding may thus not be surprising, since the triad of fever, cough and shortness of breath is a common clinical presentation of respiratory tract infections usually experienced by many in Uganda.

The most cited sources of information on COVID-19 were the national ministry of health; the news media like TV, radios and newspapers, and social media. Reliance on messages through official government sources through TV, radio and official websites which are usually censored has previously been reported in Uganda [21] and remains a widely used source of information in other settings [28]. The reliance on social media as found in the current study is not unexpected since it has become a widely popular source of information among many population groups [8] [15] [21] [27] owing to its ease of accessibility and cost-effectiveness. However, the spread of misinformation through social media remains of great concern [8] [29], a situation which, as asserted by Shu et al. (2017), can have devastating effects on society [30]. Importantly, while many students in the current study used social media for COVID-19 information, only 
$13 \%$ trusted its worthiness. This is reassuring as it means that those engaged with these channels may scrutinize the information presented to them. Nonetheless, social media continues to play a vital role in educating the public about COVID-19 [24].

\subsection{Attitude Related to COVID-19}

This study reveals a generally negative attitude related to COVID-19 among the undergraduate students, only $47.2 \%$ had a positive attitude overall. The attitude was significantly influenced by the study program and the year of study. Students undertaking health-related programs were three times as likely to have a positive attitude towards COVID-19 as those pursuing non-health-related programs. Similarly, students in their second year of study onwards, regardless of the program being undertaken were significantly more likely to have a positive attitude towards COVID-19 than the first-year students. This finding bodes well with that conducted among purely medical students [21]. Unlike the report by other authors [5] [16], there was no statistically significant difference in attitude score by gender among the undergraduate students in the current study.

When asked about the ability of the country to contain the current COVID-19 pandemic, the majority of the respondents held a pessimistic attitude: only $34.8 \%$ had confidence that Uganda can win the battle against COVID-19, while only $41.0 \%$ were confident that the school environment was enabling in preventing the spread of COVID-19. This finding mirrors that from previous studies in Pakistan [15] and Uganda [17] where a large number of respondents did not believe in the ability of the government to combat the COVID-19 epidemic but contrasts with findings from China, Saudi Arabia and Nepal [5] [6] [26]. This is rather surprising given the government's prompt response in taking stringent control and precautionary measures against COVID-19 but is in tandem with the assertion that people tend to express negative emotions, such as anxiety and panic, during a pandemic that could affect their attitude [31]. The pessimistic attitude could have also been informed by the ongoing rise in the number of cases in the country, the general lack of trust in the national health system, and the information gap between the population and the government. There is thus a need for authorities in government and the health ministry to instil confidence in the common man, in general, using all the available channels.

\subsection{Practices Related to COVID-19 Prevention}

Overall, only $42.7 \%$ of the respondents in the current study demonstrated good practice towards COVID-19 prevention. Male students were twice as likely to exhibit good preventive practices as females. This finding contrasts with that on Middle East Respiratory Syndrome Coronavirus (MERS-CoV) among the Saudis population where males were significantly less likely than females to take safety precautions and prevention [27]. On the other hand, a report by Ping and colleagues (2020) showed no statistically significant difference in preventive prac- 
tices between groups by gender [16]. The finding of positive practice among the male gender has, however, previously been reported [32] and is of significance in that generally, men and late adolescents are more likely to engage in risk-taking behaviour [33] [34] as was evidenced in China where male gender was significantly associated with the practice of defying the principle of social distancing [6].

SARS-CoV-2 is a highly infectious agent just like most viral infections and has been documented to be highly contagious among people in close proximity [35]. However, while close to three-quarters $(72 \%)$ of the respondents had refrained from shaking hands in the period preceding the study, more than half either frequently or occasionally associated with a crowded environment-defying the recommended social distancing measures. Likewise, up to $45.3 \%$ of the respondents either inconsistently or never wore a face mask when leaving home for public places, while $43.5 \%$ inconsistently washed their hands before and after touching anything. This is concerning and comes on the backdrop when the national ministry of health has produced a guide on COVID-19 to provide residents with facts and precautionary messages. It, however, calls for more concerted effort in intensifying education and behaviour change communication to the population, especially in as far as dissemination of the available information, education and communication (IEC) materials are concerned. This approach is supported by evidence from a Saudi's study where the provision of education and outreach materials to increase public understating of the disease and influence behavioural change was associated with high rates of adoption of good and safe practices towards COVID-19 [26].

The majority of the respondents in the current study would self-quarantine or go to the hospital for treatment if they had a fever and dry cough, while $1.2 \%$ would hide or rather go to a clinic or buy some medicine and self-medicate. Similarly, the majority of the undergraduate students would proactively report to the authority and stay in quarantine as required if they had close contact with a confirmed case of COVID-19, though 3.1\% would rather keep the information to themselves. Concerning what they would do if a colleague or one of their classmates who got cured of COVID-19 wanted to meet them or were to attend class with them, the majority of the respondents would meet or attend class with their classmates and show them more kindness, while $3.1 \%$ would rather find an excuse to keep away from such a colleague or classmate. While these findings are largely reassuring, the wrong actions that would be demonstrated by the minority cannot be ignored, especially when it causes stigmatization, since this would hinder other students from coming forward.

\section{Limitations of the Study}

The convenience sampling technique used in this study could have introduced sampling bias which, together with the relatively small sample size, could limit the representativeness of the study findings. 


\section{Conclusion}

Overall, the current findings suggest an unsatisfactory COVID-19-related KAP among undergraduate students. Although the government has taken major steps to create public awareness through various channels to limit the spread of the disease, there is a need for more educational program and behaviour change communication, tailored to target undergraduate students, especially in the non-health-related disciplines.

\section{Acknowledgements}

We acknowledge the participants for sparing their time to participate in the study.

\section{Conflicts of Interest}

No competing interests were disclosed.

\section{Grant Information}

The author(s) declared that no grants were involved in supporting this work.

\section{Availability of Data and Materials}

All data underlying the results are available as part of the article and no additional source data are required.

\section{References}

[1] World Health Organization. Weekly Epidemiological Update on COVID-19, 30 March 2021.

https://www.who.int/publications/m/item/weekly-epidemiological-update-on-COV ID-19---31-march-2021

[2] Hoda, J. (2016) Identification of Information Types and Sources by the Public for Promoting Awareness of Middle East Respiratory Syndrome Coronavirus in Saudi Arabia. Health Education Research, 31, 12-23.

[3] Li, Q., Guan, X., Wu, P., Wang, X., Zhou, L., Tong, Y., et al. (2020) Early Transmission Dynamics in Wuhan, China, of Novel Coronavirus-Infected Pneumonia. The New England Journal of Medicine, 382, 1199-1207.

[4] Lauer, S., Grantz, K., Bi, Q., et al. (2020) The Incubation Period of Coronavirus Disease 2019 (COVID-19) from Publicly Reported Confirmed Cases: Estimation and Application. Annals of Internal Medicine, 172, 577-582.

https://doi.org/10.7326/M20-0504

[5] Asraf, H., Garima, T., Singh, B.M., Ram, R. and Tripti, R.P. (2020) Knowledge, Attitudes, and Practices towards COVID-19 among Nepalese Residents: A Quick Online Cross-Sectional Survey. Asian Journal of Medical Sciences, 11, 6-11. https://doi.org/10.3126/ajms.v11i3.28485

[6] Zhong, B.-L., Luo, W., Li, H.-M., Zhang, Q.-Q., Liu, X.-G., Li, W.-T., et al. (2020) Knowledge, Attitudes, and Practices towards COVID-19 among Chinese Residents during the Rapid Rise Period of the COVID-19 Outbreak: A Quick Online Cross-Sectional Survey. International Journal of Biological Sciences, 16, 1745-1752. 


\section{https://doi.org/10.7150/ijbs.45221}

[7] CDC (2021) Coronavirus Disease 2029 (COVID-19). Symptoms of Coronavirus. https://www.cdc.gov/coronavirus/2019-ncov/symptoms-testing/symptoms.html

[8] Abdelhafiz, A.S., Mohammed, Z., Ibrahim, M.E., Ziady, H.H., Alorabi, M., Ayyad, M. and Sultan, E.A. (2020) Knowledge, Perceptions, and Attitude of Egyptians towards the Novel Coronavirus Disease (COVID-19). Journal of Community Health, 45, 881-890. https://doi.org/10.1007/s10900-020-00827-7

[9] Chen, N., Zhou, M., Dong, X., Qu, J., Gong, F., Han, Y., et al. (2020) Epidemiological and Clinical Characteristics of 99 Cases of 2019 Novel Coronavirus Pneumonia in Wuhan, China: A Descriptive Study. The Lancet, 395, 507-513. https://doi.org/10.1016/S0140-6736(20)30211-7

[10] Li, J.Y., You, Z., Wang, Q., et al. (2020) The Epidemic of 2019-Novel-Coronavirus (2019-nCoV) Pneumonia and Insights for Emerging Infectious Diseases in the Future. Microbes and Infection, 22, 80-85. https://doi.org/10.1016/j.micinf.2020.02.002

[11] World Health Organisation (2020) Infection Prevention and Control during Health Care When Novel Coronavirus (nCoV) Infection Is Suspected. World Health Organization, Geneva.

[12] World Health Organisation (2020) Coronavirus Disease (COVID-19) Advice for the Public.

https://www.who.int/emergencies/diseases/novelcoronavirus-2019/advice-for-public

[13] Mohamad, E. and Azlan, A.A. (2020) COVID-19 and Communication Planning for Health Emergencies. Jurnal Komunikasi: Malaysian Journal of Communication, 36, $1-2$.

[14] Kish, L. (1965) Survey Sampling. John Wiley and Sons, New York, 59-60.

[15] Ikhlaq, A., Bint-E-Riaz, H., Bashir, I. and Ijaz, F. (2020) Awareness and Attitude of Undergraduate Medical Students towards 2019-Novel Coronavirus. Pakistan Journal of Medical Sciences, 36, S32-S36. https://doi.org/10.12669/pjms.36.COVID19-S4.2636

[16] Peng, Y.L., Pei, C.C., Zheng, Y., Wang, J., Zhang, K., Zheng, Z.H. and Zhu, P. (2020) Knowledge, Attitude and Practice Associated with COVID-19 among University Students: A Cross-Sectional Survey in China. https://www.researchgate.netpublication340638267 knowl https://doi.org/10.21203/rs.3.rs-21185/v1

[17] Olum, R., Chekwech, G., Wekha, G., Nassozi, D.R. and Bongomin, F. (2020) Coronavirus Disease-2019: Knowledge, Attitude, and Practices of Health Care Workers at Makerere University Teaching Hospitals, Uganda. Frontiers in Public Health, 8 , 181. https://doi.org/10.3389/fpubh.2020.00181

[18] Ministry of Health (2020) National Guidelines for Management of COVID-19, April. https://www.health.go.ugcoviddocumentnational-guide

[19] Goni, M.D., Hasan, H., Naing, N.N., Wan-Arfah, N., Deris, Z.Z., Arifin, W.N. and Baaba, A.A. (2019) Assessment of Knowledge, Attitude and Practice towards Prevention of Respiratory Tract Infections among Hajj and Umrah Pilgrims from Malaysia in 2018. International Journal of Environmental Research and Public Health, 16, 4569. https://doi.org/10.3390/ijerph16224569

[20] Arbiol, J., Orencio, P.M., Nomura, H., Takahashi, Y. and Yabe, M. (2016) Knowledge, Attitude and Practices towards Leptospirosis among Lakeshore Communities of Calamba and Los Baños, Laguna, Philippines. Agriculture, 6, 18. https://doi.org/10.3390/agriculture6020018 
[21] Olum, R., Kajjimu, J., Kanyike, A.M., Chekwech, G., Wekha, G., Nassozi, D.R., et al. (2020) Perspective of Medical Students on the COVID-19 Pandemic: Survey of Nine Medical Schools in Uganda. JMIR Public Health and Surveillance, 6, e19847. https://doi.org/10.2196/19847

[22] Taghrir, M.H., Borazjani, R. and Shiraly, R. (2020) COVID-19 and Iranian Medical Students; a Survey on Their Related-Knowledge, Preventive Behaviours and Risk Perception. Archives of Iranian Medicine, 23, 249-254. https://doi.org/10.34172/aim.2020.06

[23] Wadood, M.A., Mamun, A., Rafi, M.A., Islam, M., Mohd, S., Lee, L.L., et al. (2020) Knowledge, Attitude, Practice and Perception Regarding COVID-19 among Students in Bangladesh: A Survey in Rajshahi University. https://doi.org/10.1101/2020.04.21.20074757

[24] Sheeliya, W., Manahil, O. and Ghada, N.M. (2020) Knowledge, Attitude and Practice on Prevention of Airborne and Droplet Infections during the Outbreak of Corona Virus among the College Students in University of Bisha, Saudi Arabia. IJCRR, 11, 20773-20776.

[25] Heung, Y.Y., Wong, K.Y., Kwong, W.Y., To, S.S., Wong, H.C. and Wong, D. (2005) Severe Acute Respiratory Syndrome Outbreak Promotes a Strong Sense of Professional Identity among Nursing Students. Nurse Education Today, 25, 112-118. https://doi.org/10.1016/j.nedt.2004.11.003

[26] Al-Hanawi, M.K., Angawi, K., Alshareef, N., Qattan, A.M.N., Helmy, H.Z., Abudawood, Y., et al. (2020) Knowledge, Attitude and Practice toward COVID-19 among the Public in the Kingdom of Saudi Arabia: A Cross-Sectional Study. Frontiers in Public Health, 8, 217. https://doi.org/10.3389/fpubh.2020.00217

[27] ALdowyan, N.M., Ahmed, A.S. and El-Gharabawy, R.M. (2017) Knowledge, Attitude and Practice (KAP) Study about the Middle East Respiratory Syndrome Coronavirus (MERS-CoV) among Population in Saudi Arabia. International Archives of Medicine, 10, 1-12. https://doi.org/10.3823/2524

[28] Austrian, K., Pinchoff, J., Tidwell, J.B., White, C., Abuya, T., Kangwana, B., et al. (2020) COVID-19 Related Knowledge, Attitudes, Practices and Needs of Households in Informal Settlements in Nairobi, Kenya. Bulletin of the World Health Organization.

[29] Chou, W., Oh, A. and Klein, W.M.P. (2020) Addressing Health-Related Misinformation on Social Media. JAMA, 320, 2417-2418.

https://doi.org/10.1001/jama.2018.16865

[30] Shu, K., Sliva, A., Wang, S., Tang, J. and Liu, H. (2017) Fake News Detection on Social Media: A Data Mining Perspective. ACM SIGKDD Explorations Newsletter, 19, 22-36. https://doi.org/10.1145/3137597.3137600

[31] Blendon, R.J., Benson, J.M., DesRoches, C.M., Raleigh, E. and Taylor-Clark, K. (2004) The Public's Response to the Severe Acute Respiratory Syndrome in Toronto and the United States. Clinical Infectious Diseases, 38, 925-931. https://doi.org/10.1086/382355

[32] Mohamad, E., Azlan, A., Hamzah, M., Tham, J. and Ayub, S. (2020) Public Knowledge, Attitudes and Practices towards COVID-19: A Cross-Sectional Study in Malaysia. PLoS ONE, 15, e0233668. https://doi.org/10.1101/2020.04.29.20085563

[33] Duell, N., Steinberg, L., Icenogle, G., Chein, J., Chaudhary, N., Di Giunta, L., et al. (2018) Age Patterns in Risk Taking Across the World. Journal of Youth and Adolescence, 57, 1052-1072. https://doi.org/10.1007/s10964-017-0752-y

[34] Pawlowski, B., Atwal, R. and Dunbar, R. (2008) Sex Differences in Everyday 
Risk-Taking Behavior in Humans. Evolutionary Psychology, 6, 29-42. https://doi.org/10.1177/147470490800600104

[35] CDC (2020) Centres for Disease Control and Prevention: Coronavirus (COVID-19). https:/www.cdc.gov/coronavirus/2019-nCoV/index.html 